\title{
Analisa Beban Lateral Akibat Gempa Dengan Metode Statik Ekivalen
}

\author{
Rafki Imani ${ }^{1}$, Rita Nasmirayanti ${ }^{2}$, Utami Dewi Arman ${ }^{3}$, Afrilda Sari $^{4}$ \\ Fakultas Teknik, Universitas Putra Indonesia "YPTK" Padang ${ }^{1,2,3,4}$ \\ Email: rafimani17@yahoo.co.id ${ }^{1}$, tathen94@gmil.com², udewi2679@gmail.com³, \\ afrildasari@yahoo.com ${ }^{4}$ \\ DOI: http://dx.doi.org/10.31869/rtj.v4i1.2339
}

\begin{abstract}
Perencanaan gedung bertingkat harus dibangun sesuai dengan standar ketahanan gempa, agar tidak menyebabkan jatuhnya korban jiw terhadap manusia yang ada di dalamnya. Penelitian ini dilakukan untuk menentukan gaya geser beban lateral terhadap gedung RS H. Hanafie yang terdapat di Kabupaten Muaro Bungo Provinsi Jambi. Metode yang digunakan adalah metode analisis statik ekivalen dengan hasil penelitian diperoleh gaya geser arah $X=3,85 \mathrm{kN}$ dan arah $Y=57,23 \mathrm{kN}$ pada periode 1 detik.
\end{abstract}

Keywords: Metode statik ekivalen, gempa, RS H. Hanafie Muaro Bungo.

\section{PENDAHULUAN}

Gempabumi adalah bencana paling besar dampaknya terhadap wilayah Indonesia, dimana kondisi Indonesia yang berada pada batas pertemuan tiga lempeng tektonik besar dunia yaitu lempeng Eurasia, lempeng Pilipina dan lempeng Indo-Australia [1]. Keruntuhan bangunan akibat gempa yang dapat menyebabkan jatuhnya korban jiwa, adalah karena buruknya kualitas struktur. Struktur yang dibangun di wilayah yang dekat dengan sumber gempa akan memiliki kemungkinan besar menyebabkan kegagalan. Disamping itu, pengaruh ketinggian suatu struktur juga akan memiliki peluang besar terkena dampak risiko gempa dibandingkan dengan bangunan yang rendah.

\section{Beban Lateral akibat Gempa}

Struktur yang bertingkat tinggi harus didisain tahan terhadap beban lateral/horizontal yang langsung berpengaruh pada struktur bawah bangunan, seperti beban yang diakibatkan oleh getaran gempa. Getaran akibat gempa ini biasanya bergerak horizontal dan vertikal atau kombiansi keduanya ( $\operatorname{arah} \mathrm{X}$, $\mathrm{Y}, \mathrm{Z}$ ), sehingga bangunan harus didisain dengan memperhatikan beban lateral tersebut [2].

Beban lateral yang berasal dari gempa akan menyebabkan bangunan bergeser. Pergeseran ini akan didistribusikan ke semua struktur tingkat di atasnya. Jika pengaruh pergeseran ini melebihi beban geser maksimum maka struktur akan mengalami keruntuhan. Untuk menghindari kegagalan struktur tersebut maka perlu dilakukan perencanaan dan evaluasi struktur, agar dampak gempa dapat diminamilisir dan bangunan yang didirikan bisa tahan gempa.

Umumnya evaluasi struktur dilakukan dengan analisa beban statik ekivalen, analisa beban dinamik ragam respon spectrum dan analisa beban dinamik ragam time history. Metode yang paling baik adalah analisa beban dinamik ragam time history, namun membutuhkan waktu yang lama [3]. Untuk keperluan praktis di lapangan maka metode analisis beban statik ekivalen lebih dipilih, tetapi hanya ditujukan untuk bangunan regular horizontal dan vertikal saja, yaitu bangunan dengan ketinggian $40 \mathrm{~m}$ dan 10 lantai [4]. Acuan untuk perencanaan konstruksi ramah gempa di Indonesia ini diatur dalam Standar SNI-03-1726:2012 tentang Tata Cara Perencanaan Ketahanan Gempa untuk Struktur Gedung dan Non Gedung [5].

Beban Gempa Statik Ekivalen

Gaya statik ekivalen merupakan gaya yang sama besar dengan beban gempa yang mempengaruhi struktur pada batas tertentu yang tidak menimbulkan tegangan yang berarti [6] (Latuheru\&Prasojo). Berdasarkan SNI-031726:2012, analisa statik ekivalen didasarkan pada perhitungan sebagai berikut:

(1) Beban geser $V$ struktur bawah akibat gempa:

$$
V=C s . W
$$


dengan,

$$
\begin{aligned}
C s= & \frac{S_{D s}}{T\left(\frac{R}{I e}\right)} \\
C s= & \frac{S_{D 1}}{T\left(\frac{R}{I e}\right)} \\
C s= & 0,044 . S D s . \text { Ie } \geq 0,01
\end{aligned}
$$

Dimana,

$$
\begin{aligned}
C S= & \text { koefisien respon seismik } \\
W= & \text { berat seismik efektif } \\
S_{D S}= & \text { koefisien percepatan respon } \\
& \text { spektrum disain periode pendek } \\
S_{D I}= & \text { koefisien percepatan respon } \\
& \text { disain spektrum periode } 1 \text { detik } \\
R= & \text { faktor modifikasi respon } \\
I e= & \text { faktor keutamaan gempa, } \\
& \text { besarnya diatur berdasarkan } \\
& \text { kategori gempa dalam SNI-03- } \\
& 1726-2012
\end{aligned}
$$

(2) Gaya lateral gempa $F_{x}$ dihitung dengan:

$$
F_{x}=C_{V X} \cdot V
$$

dengan,

$$
C_{V X}=\frac{W_{x} \cdot h_{x}^{k}}{\sum_{i=1}^{n} W_{i} \cdot h_{i}^{k}} V
$$

dimana,

$V$ = gaya lateral disain total $\left(F_{x}\right)$ atau gaya geser di dasar struktur $(\mathrm{kN})$

$W_{i}\left(W_{x}\right)=$ berat seismik efektif total struktur yang dikenakan pada tingkat $i$ atau $x$

$h_{i}\left(h_{x}\right)=$ tinggi struktur $(\mathrm{m})$ dari dasar sampai tingkat $i$ atau $x$

$k=$ eksponen yang terkait dengan perioda struktur, dimana nilainya adalah, $\quad k=1$ untuk struktur yang mempunyai perioda $T \leq 0,5$ detik, $k=2$ untuk struktur yang mempunyai perioda $T \geq 2,5$ detik, dan untuk $k$ harus sebesar 2 atau ditentukan dengan interpolasi linier antara 1 dan 2 untuk struktur yang mempunyai perioda antara $0,5 \leq T \leq 2,5$ detik.

\section{Periode Fundamental Strutur T}

Periode fundamental stuktur $(T)$, tidak boleh melebihi hasil koefisien untuk batasan di atas pada periode yang dihitung $\left(C_{u}\right)$.
Berdasarkan Tabel 1, sebagai alternatif untuk keperluan analisis dalam menentukan menentukan periode fundamental stuktur $(T)$, dapat menggunakan periode bangunan pendekatan, $T_{A}$. Periode Fundamental pendekatan $\left(T_{A}\right)$, harus ditentukan dari persamaan berikut,

$$
T_{A}=C t . h_{n}{ }^{x}
$$

dengan $h_{n}{ }^{x}$ adalah ketinggian stuktur, dalam meter $(\mathrm{m})$.

Tabel 1. Koefisien batas atas periode hitung (SNI-03-1726-2012).

\begin{tabular}{|c|c|}
\hline $\begin{array}{c}\text { Parameter percepatan respons spektral desain } \\
\text { pada 1 detik, } S_{D 1}\end{array}$ & Koefisien $C_{u}$ \\
\hline$\geq 0,4$ & 1,4 \\
\hline 0,3 & 1,4 \\
\hline 0,2 & 1,5 \\
\hline 0,15 & 1,6 \\
\hline$\leq 0,1$ & 1,7 \\
\hline
\end{tabular}

Respon Spektrum

Respon spektrum adalah plot grafik spektrum antara periode getar stuktur $T$ terhadap respon-respon maksimum berdasarkan rasio redaman dan gempa tertentu. Respon-respon maksimum (spectral displacement, $\left.S_{D}\right)$ kecepatan maksimum (spectral velocity, $S V$ ) atau percepatan maksimum (spectral acceleration, SA) masa stuktur single degree of freedom (SDOF) (Widodo, 2001).

Spektrum percepatan akan berhubungan dengan gaya geser maksimum yang bekerja pada dasar stuktur. Terdapat dua macam respons spektrum yaitu respon spektrum elastik dan respon spektrum inelastik. Spektrum elastik adalah suatu spektrum respon spektrum yang didasarkan atas respon elastik suatu stuktur, sedangkan spektrum inelastik adalah respon spectrum yang di-scale down dari spektrum elastik dengan nilai daktilitas tertentu.

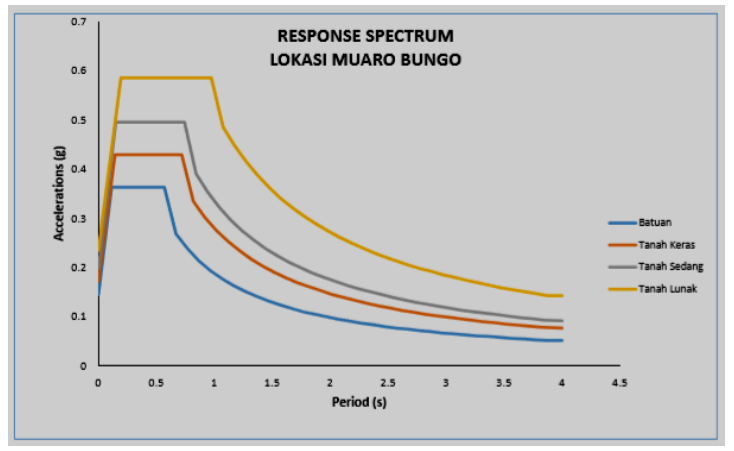

Gambar 1. Respon spektrum berbagai jenis tanah di Muaro Bungo Jambi. 
Respon Spektrum

Kondisi tanah sangat mempengaruhi perencanaan bangunan tahan gempa. Terdapat empat tipe jenis tanah yaitu tanah batuan, tanah keras, tanah sedang, dan tanah lunak. Jenis tanah ini diklasifikasikan berdasarkan SNI-03-1726-2012, seperti Tabel 2.

Tabel 2. Klasifikasi jenis tanah.

\begin{tabular}{|c|c|c|c|}
\hline Kelas situs & $\bar{v}_{t}$ (m/detik) & $N \operatorname{atau}_{N_{c k}}$ & $\bar{S}_{\mathrm{s}}(\mathrm{kPa})$ \\
\hline SA (batuan keras) & $>1500$ & N/A & N/A \\
\hline SB (batuan) & 750 sampai 1500 & N/A & N/A \\
\hline $\begin{array}{l}\text { SC (tanah keras, sangat } \\
\text { padat dan batuan } \\
\text { lunak) }\end{array}$ & 350 sampai 750 & $>50$ & $\geq 100$ \\
\hline SD (tanah sedana) & 175 samnai 350 & 15 samnai 50 & 50 samnai 100 \\
\hline
\end{tabular}

\section{METODE PENELITIAN}

Penelitian ini dilakukan terhadap gedung RS. H. Hanafie di Kabupaten Muara Bungo, Provinsi Jambi pada bulan Agustus sampai dengan akhir Oktober 2009. Metode penelitian ini adalah metode analisis dan dibantu dengan software ETABS. Analisis dilakukan dengan cara permodelan gedung mulai dari kolom, balok, plat lantai dan struktur gedung lainnya, beserta pembebanannya ke dalam software.

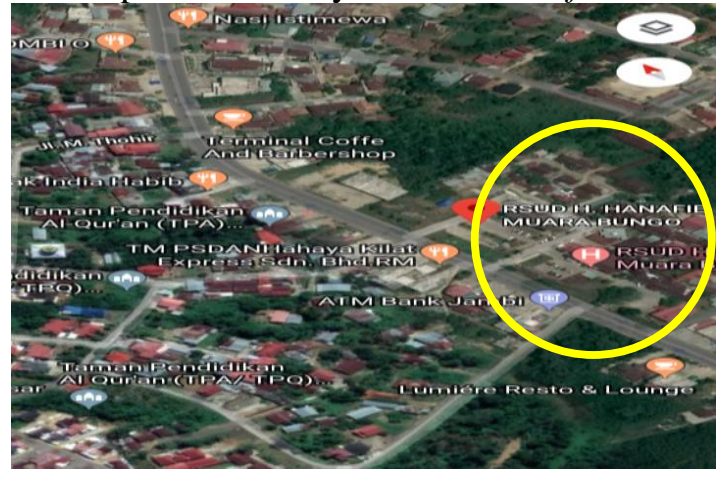

Gambar 2. Lokasi gedung RS H. Hanafie di Muaro Bungo Provinsi Jambi.

\section{Permodelan}

Permodelan struktur yang akan ditinjau adalah struktur beton bertulang 3 tingkat. Struktur bangunan difungsikan sebagai gedung rawat inap rumah sakit, dan beban hidupnya diatur berdasarkan SNI 1727-2013, yaitu sebesar $250 \mathrm{~kg} / \mathrm{m}^{2}$. Gambar pemodelan dapat dilihat pada Gambar 3 di bawah.
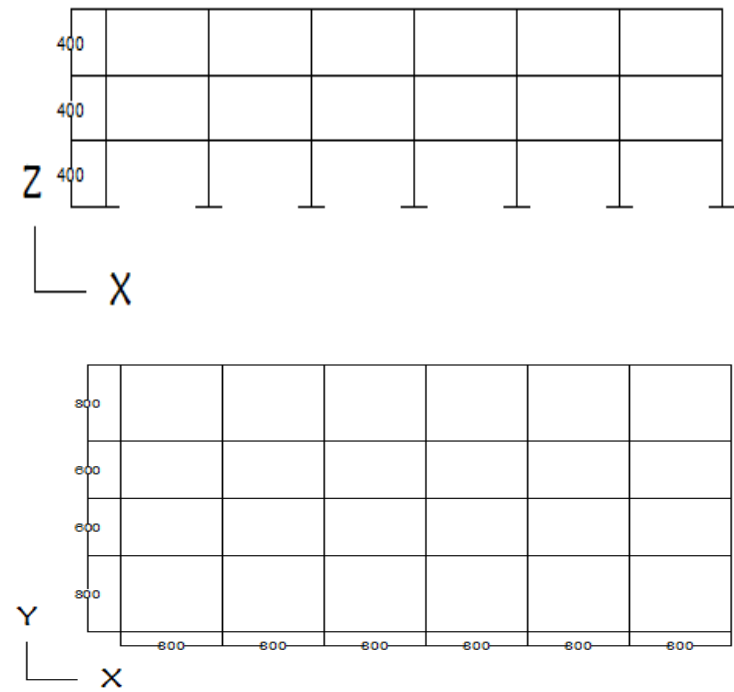

Gambar 3. Permodelan struktur 3 tingkat.

\section{Data Struktur}

Data struktur yang digunakan adalah sebagai berikut:

1. Material

a. Kuat tekan beton $\left(f^{\prime} c\right)=25 \mathrm{Mpa}$

b. Berat jenis beton $(W)=2400 \mathrm{~kg} / \mathrm{m}^{3}$

c. Modulus elastisitas, $E c=20.000 \mathrm{Mpa}$

d. Tegangan leleh $(f y)=300 \mathrm{Mpa}$

2. Elemen struktur
a. Pelat
$=15 \mathrm{~cm}$
b. Kolom tingkat 1-2
$=55 / 55 \mathrm{~cm}$
c. Balok
$=35 / 65 \mathrm{~cm}$
d. Sistem struktur adalah SPRMK

\section{HASIL DAN PEMBAHASAN}

Lokasi bangunan termasuk kelas situs SD (kondisi tanah sedang) dengan kategori risiko IV (Gambar 1) dan faktor keutamaan gempa $(I e)=1,50$.

Pembebanan

Data Beban mati merupakan beban dari semua elemen gedung yang bersifat permanen termasuk peralatan tetap yang merupakan bagian yang tak terpisahkan dari gedung. Beban mati yang bekerja yaitu; beton bertulang $\left(2400 \mathrm{~kg} / \mathrm{m}^{3}\right)$, pasir $\left(1600 \mathrm{~kg} / \mathrm{m}^{3}\right)$, adukan semen dan spasi $\left(21 \mathrm{~kg} / \mathrm{m}^{3}\right)$, keramik $\left(24 \mathrm{~kg} / \mathrm{m}^{3}\right)$. Beban hidup merupakan beben yang bekerja pada lantai bangunan, yang berdasarkan fungsi ruang yang digunakan. Pembagian beban hidup sebagai berikut:
a. atap $=100 \mathrm{~kg} / \mathrm{m}^{3}$,
b. $\quad$ tangga $=300 \mathrm{~kg} / \mathrm{m}^{3}$, dan
c. lantai rumah sakit $=250 \mathrm{~kg} / \mathrm{m}^{3}$.

Perhitungan Berat Struktur Tiap Lantai 
Berat lantai-3

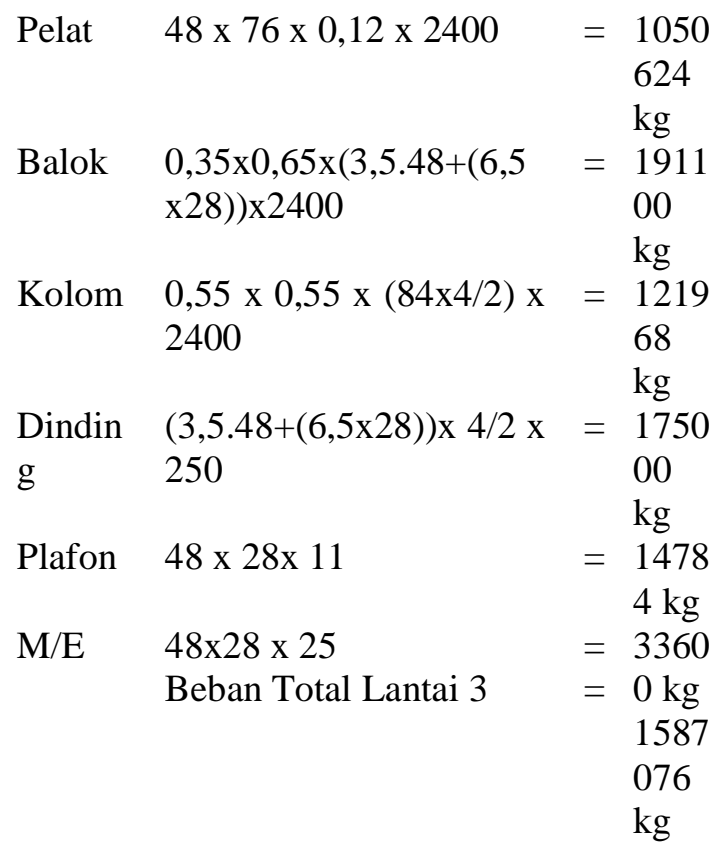

Berat lantai-2

Berat lantai-1

Berat total lantai 1 sampai dengan lantai 3 adalah $5179216 \quad \mathrm{~kg} \quad(5179,26 \mathrm{kN})$. Berdasarkan peta dalam SNI-03-1726-2012, bangunan mempunyai nilai $S_{1}=10.31 \mathrm{~g}$ dan $S_{2}=20,544 \mathrm{~g}$, dan nilai $F_{A}=1,365$ dan $F_{V}=1,78$.

\section{Nilai Respon Spektrum}

Besar nilai respon spektrum percepatan perioda pendek $\left(S_{\mathrm{MS}}\right)$ dan perioda 1 detik $\left(\mathrm{S}_{\mathrm{M} 1}\right)$.

$$
\begin{aligned}
& S_{M S}=F_{a} \cdot S_{S}=1,365 \times 0,544 \mathrm{~g}=0,743 \mathrm{~g} \\
& S_{M 1}=F_{V} \cdot S_{1}=1,78 \times 0,31 \mathrm{~g}=0,552 \mathrm{~g}
\end{aligned}
$$

sehingga:

$$
\begin{aligned}
& S_{D S}=\frac{2}{3} S_{M S}=\frac{2}{3} \times 0,743 \mathrm{~g}=0,495 \mathrm{~g} \\
& S_{D 1}=\frac{2}{3} S_{M 1}=\frac{2}{3} \times 0,552 \mathrm{~g}=0,368 \mathrm{~g}
\end{aligned}
$$

Nilai $T_{0}$ dan $T_{1}$ dihitung dengan persamaan:

$$
\begin{aligned}
& T_{0}=0,2\left(\frac{S_{D 1}}{S_{D S}}\right) \\
& T_{1}=\frac{S_{D 1}}{S_{D S}}
\end{aligned}
$$

Untuk $\left(0 \leq T<T_{0}\right)$ :

$$
\left.S_{A}=S_{D S}\left(0,4+0,6 T_{0}\right)\right)
$$

Untuk $\left(T_{0}-T_{\mathrm{s}}\right) ; S_{A}=S_{D S}$

Untuk $\left(T>T_{s}\right) ; S_{A}=S_{D l} . T$

\section{Periode Getar}

Berdasarkan SNI-03-1726-2012, periode fundamental struktur dalam arah yang ditinjau harus diperoleh menggunakan properti struktur dan karakteristik deformasi elemen penahan dalam analisis yang teruji, $T_{A}=C_{t} \cdot h_{n}{ }^{x}$, dengan

\begin{tabular}{|c|c|c|}
\hline Pelat & $48 \times 76 \times 0,12 \times 2400$ & $=1050624 \mathrm{~kg}$ \\
\hline Balok & $\begin{array}{l}0,35 \times 0,65 \times(3,5.48+(6,5 \times 28)) \\
\times 2400\end{array}$ & $=191100 \mathrm{~kg}$ \\
\hline Kolom & $\begin{array}{l}0,55 \times 0,55 \times(84 \times 4 / 2) \times \\
2400\end{array}$ & $=121968 \mathrm{~kg}$ \\
\hline Dinding & $(3,5.48+(6,5 \times 28)) \times 4 / 2 \times 250$ & $=175000 \mathrm{~kg}$ \\
\hline Plafon & $48 \times 28 \times 11$ & $=14784 \mathrm{~kg}$ \\
\hline Spesi & $48 \times 28 \times 21$ & $=28224 \mathrm{~kg}$ \\
\hline $\begin{array}{l}\text { Kerami } \\
\mathrm{k}\end{array}$ & $48 \times 28 \times 24$ & $=32256 \mathrm{Kg}$ \\
\hline $\mathrm{M} / \mathrm{E}$ & $\begin{array}{l}48 \times 28 \times 25 \\
\text { Beban Total }\end{array}$ & $\begin{array}{l}=33600 \mathrm{~kg} \\
=1647556 \mathrm{~kg}\end{array}$ \\
\hline Pelat & $48 \times 76 \times 0,12 \times 2400$ & $=1050624 \mathrm{~kg}$ \\
\hline Balok & $\begin{array}{l}0,35 \times 0,65 \times(3,5.48+(6,5 \times 28)) \\
\times 2400\end{array}$ & $=191100 \mathrm{~kg}$ \\
\hline Kolom & $0,55 \times 0,55 \times(84 \times 4) \times 2400$ & $=243936 \mathrm{~kg}$ \\
\hline Dinding & $(3,5.48+(6,5 \times 28)) \times 4 \times 250$ & $=350000 \mathrm{~kg}$ \\
\hline Platfond & $48 \times 28 \times 11$ & $=14784 \mathrm{~kg}$ \\
\hline Spesi & $48 \times 28 \times 21$ & $=28224 \mathrm{~kg}$ \\
\hline Keramik & $48 \times 28 \times 24$ & $=32256 \mathrm{Kg}$ \\
\hline $\mathrm{M} / \mathrm{E}$ & $48 \times 28 \times 25$ & $=33600 \mathrm{~kg}$ \\
\hline & Beban Total Lantai & $=1944584 \mathrm{~kg}$ \\
\hline
\end{tabular}
$h_{n}$ adalah ketinggian stuktur (m), di atas dasar sampai tingkat 3 stuktur $(12 \mathrm{~m})$, koefisien $C_{t}=0,0466$ dan $x=0,9$ yang ditentukan dari Tabel 15 SNI-03-1726-2012. Dari program analisis struktur diperoleh periode fundamental $T_{c}=0,5810$ detik, sehingga

$T_{A}=C_{t} \cdot h_{n}{ }^{x}=0,0466 \times 120,9=0,430$ detik

$S_{D 1}=0,368 \mathrm{~g}$

$C_{u}=1,4$ (Tabel 14 SNI - $03-1726$ - 2012)

$T_{\text {maks }}=C_{u} \cdot T_{A}=1,4 \times 0,430=0,602$ detik

Jika $T_{c}>C_{u} \cdot T_{A}$, maka gunakan $T=C_{u} \cdot T_{a}$, jika $T_{A}<T_{c}<C_{u} \cdot T_{a}$, maka gunakan $T=T_{c}$ dan jika $T_{c}<T_{A}$, gunakan $T=T_{A}$, dengan $T_{c}$ adalah perioda fundamental struktur yang diperoleh dari program analisis struktur.

Berdasarkan ketentuan di atas, maka digunakan $T_{A}<T_{c}<C_{u} \cdot T_{A}$ dimana $0,430<0,5810<0,602$, sehingga periode 


\begin{tabular}{|c|c|c|c|c|c|c|c|}
\hline \multirow[t]{2}{*}{$\begin{array}{c}\text { Lantai } \\
\text { ke- } i\end{array}$} & \multirow{2}{*}{\begin{tabular}{|c|}
$h_{i}$ \\
$(\mathrm{~m}$ \\
)
\end{tabular}} & \multirow{2}{*}{$h_{i}^{k}$} & \multirow[t]{2}{*}{$\begin{array}{c}W_{\mathrm{i}} \\
(\mathrm{kN})\end{array}$} & \multirow{2}{*}{$\begin{array}{c}W_{i} \\
h_{i}{ }^{k} \\
(\mathrm{kN} \\
\mathrm{m})\end{array}$} & \multirow{2}{*}{$\begin{array}{c}F_{i x-y} \\
(\mathrm{kN} \\
)\end{array}$} & \multicolumn{2}{|c|}{$\begin{array}{l}\text { Untuk tiap } \\
\text { portal }\end{array}$} \\
\hline & & & & & & $\begin{array}{c}1 / \\
4 \\
F_{i x}\end{array}$ & $\begin{array}{l}1 / 6 \\
F_{i y}\end{array}$ \\
\hline 3 & 1 & $\begin{array}{l}13 \\
, 2 \\
5\end{array}$ & 1587,0 & $\begin{array}{c}21027 \\
, 7\end{array}$ & $\begin{array}{c}343,4 \\
3\end{array}$ & $\begin{array}{c}85,8 \\
5\end{array}$ & $\begin{array}{l}57, \\
23\end{array}$ \\
\hline 2 & 8 & $\begin{array}{l}8, \\
69 \\
\end{array}$ & 1647,5 & $\begin{array}{c}14316 \\
, 7\end{array}$ & $\begin{array}{c}233,8 \\
2 \\
\end{array}$ & $\begin{array}{c}58,4 \\
5\end{array}$ & $\begin{array}{l}38, \\
97\end{array}$ \\
\hline 1 & 4 & $\begin{array}{l}4, \\
22\end{array}$ & 1944,5 & $\begin{array}{c}8205 \\
79\end{array}$ & $\begin{array}{c}134,0 \\
2\end{array}$ & $\begin{array}{c}33,0 \\
5\end{array}$ & $\begin{array}{l}22, \\
33\end{array}$ \\
\hline & $\sum$ & & 5179,2 & $\begin{array}{c}43550 \\
, 19\end{array}$ & & & \\
\hline
\end{tabular}

fundamental dasar struktur adalah, $T=T_{c}=0,5810$ detik.

Gaya Geser Dasar Seismik

Koefisien respon seismik, $C_{s}$ ditentukan dengan,

$$
C s=\frac{S_{D S}}{\frac{R}{I e}}
$$

dimana

$S_{D S}=$ parameter percepatan spektrum respons desain perioda pendek $(0,495 \mathrm{~g})$.

$R=$ faktor modifikasi respons $\left(R_{X}=R_{Y}=8,0\right)$

$I e=$ faktor keutamaan gempa $(I e=1,50)$

$C_{s}=\left(0,044 . S_{D S} . I e \geq 0,01\right)<\left(C_{s}=\frac{S_{D S}}{\frac{R}{I e}}\right)<\left(C_{s}=\frac{S_{D 1}}{T\left(\frac{R}{I e}\right)}\right)$

$C_{\max }=0,044 \cdot S_{D S} \cdot I e \geq 0,01=0,044(0,495)(1,50)=0,0326$

$C_{\text {min }}=\frac{S_{D 1}}{T\left(\frac{R}{I e}\right)}=\frac{0,368}{0,5810\left(\frac{8}{1,50}\right)}=0,118$

$$
C s=\frac{S_{D S}}{\frac{R}{I e}}=\frac{0,495}{\frac{8}{1,50}}=0,0412
$$

sehingga,

$C s_{\min }<C s<C s_{\max }$

$0,0326<0,0412<0,118$

jadi besar gaya geser di dasar struktur adalah:

$V=C s . W$

$V=0,0412(5179,216)$

$V=213,383$ ton $=2133,836 \mathrm{kN}$

Gaya gempa lateral $\left(F_{x}\right)$ yang timbul di semua tingkat harus ditentukan berdasarkan:
- untuk struktur dengan periode $T \leq 0,5$ detik, $k=1$

- untuk struktur dengan periode $T \geq 2,5$ detik, maka $k=2$

- untuk struktur dengan periode $0,5 \leq T \leq 2,5$ detik, $k$ harus sebesar 2 atau ditentukan dengan interpolasi linier antara 1 dan 2 .

Jika $T=0,581$ detik, maka nilai $k$ diperoleh sebesar $k=1,04$ yang dimanipulasi dengan cara interpolasi. Perhitungan beban gempa ditampilkan dalam Tabel 3 berikut.

Tabel 3. Perhitungan beban gempa.

\section{Beban gempa arah $X$}

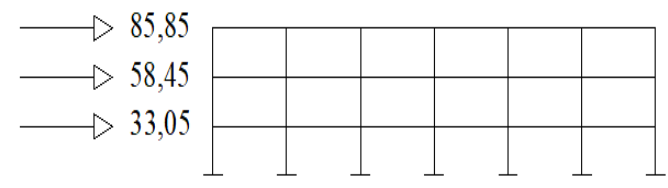

Beban gempa arah $Y$

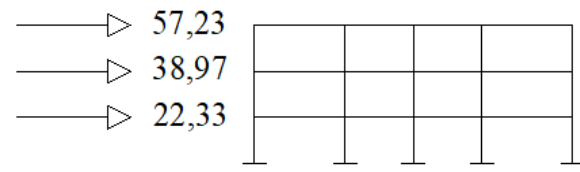

\section{PENUTUP}

Dimensi kolom utama $550 \mathrm{~mm} \times 550 \mathrm{~mm}$, balok utama $350 \mathrm{~mm} \times 650 \mathrm{~mm}$ dan dengan periode fundamental 1 detik adalah 0,581 detik. Struktur menghasilkan gaya geser pada arah $X$ pada lantai sebesar $3,85 \mathrm{kN}$ dan pada arah $Y$ sebesar 57,23 $\mathrm{kN}$ ketika terjadi periode getar gempa selama 1 detik.

\section{DAFTAR PUSTAKA}

Soelarso, Baehaki, F.D. Subhan, "Analisis

Struktur Beton Bertulang SRPMK Terhadap Beban Gempa Statik dan Dinamik dengan Peraturan SNI 1726 2012," Jurnal Fondasi, Vol 4 No 2, pp 17, 2015.

R. Fauziah, "Studi Perbandingan Beban Gempa Statik Ekuivalen dan Dinamik Time history pada Gedung Bertingkat di Yogyakarta," Jurnal Ilmiah Semesta Teknik, vol 18 No 2, pp. 190-199, 2015.

Widodo, "Respon Dinamik Struktur Elastik.," UII Press. Yogyakarta, 2001.

N. Safira, S. Sebayang, and M. Helmi, "Analisis Pengaruh Beban Gempa pada Gedung Tiga Lantai Menggunakan 
Metode Statik Ekuivalen," JRSDD, Vol.

6, No. 3, pp 273 - 282, 2018.

Standar SNI 03 1726:2012, “Tata cara perencanaan ketahanan gempa untuk struktur bangunan gedung dan non gedung," Badan Standardisasi Nasional BSN, Jakarta, 2012.

R.R. Latuheru, and R. Prasojo, "Analisa Statik Dan Dinamik Gedung 8 Lantai," Jurnal Tugas Akhir Mahasiswa Jurusan Teknik Sipil, Universitas 17 Agustus 1945, Jakarta. 